\title{
Evaluation of Yearly Water quality index and Seasonal Variation of Yamuna River at Hathikund Station Using Canadian Council of Ministers of Environment Water Quality Index (CCME) Model:
}

\author{
S. I. Abba ${ }^{1}$, G. Saini ${ }^{2}$, R. A. Abdulkadir ${ }^{3}$ \\ ${ }^{I}$ Department of PPD\&M Northwest University, Kano, Nigeria \\ ${ }^{2}$ Department of Civil Engineering Sharda University, India \\ ${ }^{3}$ Department of Electrical Engineering KUST Wudil, Nigeria
}

\begin{abstract}
The present work describes the application of Canadian Council of Ministers of the Environment Water Quality Index (CCME WQI) for Hathikund station located along with Yamuna River India city. CCME WQI was applied using six water quality parameter (DO, BOD, pH value, FC, Ammonia and WT). Based on the results obtained from the index, the Yearly water quality of Hathikund River ranged between the ranges of 2083 which indicate that river has the worst quality due to effect of various urban pollutant sources. This work confirms the need to take a serious action for monitoring the river for proper management, This work will focuses on finding the seasonal variation, deterioration, severely affected stations and complete evaluation of status of water quality of Yamuna river using the Canadian council of ministers of environment (CCME) approaches Almost 200 million people This work will focuses on finding the seasonal variation, deterioration, severely affected stations and complete evaluation of status of water quality of Yamuna river using the Canadian council of ministers of environment(CCME) approaches in India do not have access to safe and clean drinking water and $90 \%$ of the country's water resources are polluted. As per an estimate by C.P.C.B. in 2011, only $29 \%$ of wastewater generated is being treated in urban centres having population more than 50,000 in India and 71\% as untreated waste water is being discharged to our rivers, streams and lakes, making them highly polluted. (Report TOI. April 2013), so the sewage pollution caused by ordinary Indian town \& village can be imagined.
\end{abstract}

Keywords:-CCME, WOI, Faecal coliform, DO, BOD

\section{INTRODUCTION}

All life on earth depends on water. Fresh water is a critical, finite, vulnerable, renewable natural resource on the earth and plays as important role in our living environment without it life is impossible. Standing water bodies have great importance as they are recharging resources for drinking domestic and agricultural use before the civilization water quality of pond is important for health and economy of people Water is a unique resource because it is essential for all life and it constantly cycles between the land and the atmosphere. The same water that is used for crop and animal production can also be shared with the public and the aquatic and terrestrial ecosystems (Cooper et al., 1998). Water resources are of great environmental issues and studied by a wide range of specialists including hydrologists, engineers, ecologists, geologists and geo morphologists (Kumar and Dua, 2009). It has become an important issue for them as it affects not only human uses but also plant and animal life. For healthy living, potable safe water is absolutely essential. It is a basic need of all human being to get the adequate supply of safe and fresh drinking water (1).At the present time, to safeguard freshwater resources, it is important to develop a comprehensive river water quality monitoring program all over the world. A river quality monitoring program (RQMP) could be designed on the basis of the information on the existing water quality, standards, anthropological effects and the 'use' criteria. The monitored data help the planners both at the national and international levels to develop various environmental programs (2). One of the most effective ways to communicate water quality is Water Quality Index (WQI), where the water quality is assessed on the basis of calculated water quality indices. Quality of water is defined in terms of its physical, chemical, and biological parameters. However, the quality is difficult to evaluate from a large number of samples, each containing concentrations for many parameters (Almeida, 2007). Horton (1965) proposed the first WQI; a great deal of consideration has been given to the development of index methods. A water quality index provides a single number that expresses overall water quality at a certain location on several water quality parameters and turns complex water quality data into information that is understandable and useable by the general people. WQI is a mathematical instrument used to transform large quantities of water quality data into a single number which represents the water quality level while eliminating the subjective assessments of water quality and biases of individual water quality experts. Basically a WQI attempts to 
provide a mechanism for presenting a cumulatively derived, numerical expression defining a certain level of water quality (Miller et al., 1986). Comparison can be made through the WQI among the water bodies and a general analysis of water quality on different levels can be made. A water quality index is a means to summarize large amounts of water quality data into simple terms (e.g., poor, good etc.) for reporting to management and the public in a consistent manner.

\section{MATERIAL AND METHODOLOGY}

The Hathikund is a concrete barrage located on the Yamuna River in Yamuna of Haryana state, India and was approximately $38 \mathrm{~km}$ downstream from DakPatthar and $2 \mathrm{~km}$ upstream from Tajewala barrage, just upstream of newly constructed barrage. This location provides water quality after the tributaries e.g. Tons, Giri, Asan etc. of lower Himalaya region joins River Yamuna with the coordinate of $30^{\circ} 18^{\prime} 50^{\circ} \mathrm{N} 77^{\circ} 35^{\prime} 04^{\circ} \mathrm{E}$ Due to the construction of barrage at Hathnikund the water of river Yamuna has been diverted into the Western Yamuna canal (WYC) and Eastern Yamuna canal (EYC). The water abstracted at these two canals is mainly used for the purpose of irrigation. WYC originates from the right bank of the river and irrigates approximately an area of 486,000 hectares annually in Haryana state and EYC originates from the left bank of the river and irrigates approximately an area of 191,000 hectares in Uttar Pradesh state. [3]the fig 2.10 shows the locations of Hathikund at Yamuna river.

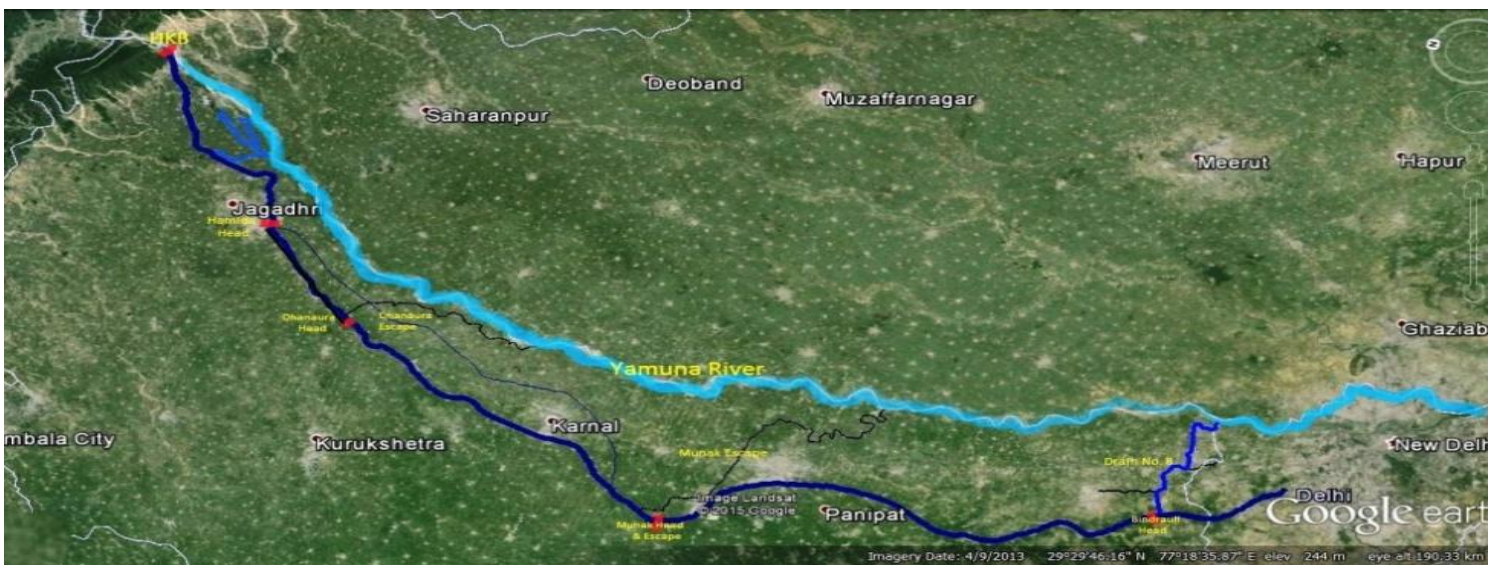

Fig: 1. Hathikund at a cross section of Yamuna (Source:https://sandrp.files.wordpress.com)

The Data was obtained from the status of water quality in India compiled by CPCB The samples were collected and analyses throughout the years from January to December from Yamuna river by central pollution control board (CPCB), The Hathikund Station at Yamuna River were selected in order to study the water quality changes using CCME for the range of 1999-2005, and for six (6) important parameters. Data source: CPCB (2000 copies, 2006).The WQI software has been prepared in Visual Basic by CCME, which can be implemented in MS- Excel for computational purpose. Instructions for the implementation are well described in the Calculator Version 1.0 (Canadian Council of Ministers of the Environment (CCME) 2001). The output is available in the form of a table and graph showing the yearly water quality index and seasonal variation of water quality index displaying the values of WQI, Monsoon seasonal variation and Non-monsoon seasonal variation. Yamuna river contained nineteen (19) stations as far the report of CPCB 2006, the data of Hathikund from 1999-2005 were imputed into the excel sheet for the six selected parameters, the status water quality of each year as far nineteen station will be obtained from that the variations, deteriorations and most severely affected stations and years will be known, The data of water quality obtained will be compared with the current available studies of water quality in some station at Yamuna river.

\subsection{The CCME Index:}

The Canadian council of minister of environment (CCME) of water quality index (WQI) is a wellaccepted and universally applicable model for evaluating the water quality index. The CCME compares observation to the benchmark were the benchmark can be water quality index or sit-specific background concentration, most applications of CCME WQI have used the national water quality standards so this acts as the advantage of index which can be applied to different countries with a few modifications. CCMEWQI compares observations to a benchmark instead of normalizing observed values to subjective rating curves, where the benchmark may be a water quality standard or site specific background concentration (CCME, 2001; Khan et al., 2003; Lumbet al., 2006). So, this acts as an advantage of the index which can be applied by the 
water agencies in different countries with little modification. To categorize water quality under this, four categories have been suggested i.e. Excellent, Good, Fair and Poor. Calculating index scores (Khan et al. 2004).

The calculation of index scores in CCME WQI method can be obtained by using the following relation:

Where:

$$
W Q I=100-\frac{\sqrt{F_{1}^{2}+F_{2}^{2}+F_{3}^{2}}}{1.732}
$$

$\boldsymbol{F}_{\mathbf{1}}$ Scope: Scope: Assess the extent of compliance with water quality guidelines over the time period of interest.

$F_{2}$ Frequency

- Assess the frequency with which the guidelines are not meet.

$F_{3}$ Amplitude: Amplitude: Assesses the amount by which guidelines are not meet

- $F_{1}=\frac{\text { Number of failed variables }}{\text { Total Number of variables }} \times 100$

- $\quad F_{2}=\frac{\text { Number of failed tests }}{\text { Total number of test }} \times 100$

- $F_{3}=\left\{\frac{\text { nse }}{0.01 n s e+0.01}\right\}$

- The amount of times an individual concentration exceed a guidelines is term as an excursion.

When the test value must not exceed the objectives:

excusion $_{i}=\frac{{\text { Failed test } \text { value }_{i}}_{\text {Objectives }_{j}}-1}{}$

When the test value must not fall below the objectives:

excusion $_{i}=\frac{\text { Objectives } j}{\text { Failed test value }}{ }_{i}-1$

The collective amount by which individual tests are out of compliance with guidelines is calculated by summing the excursions of individual tests, and dividing by the total number of tests which failed guidelines.

This variable is referred to as the normalized sum of excursions, or $n s e$.

- $n s e=\frac{\sum \text { excursionsion }}{\# \text { of tests }}$

Once the factors have been obtained, the index itself can be calculated by summing the three factors as if they were vectors. The sum of the squares of each factor is therefore equal to the square of the index.

$$
W Q I=100-\frac{\sqrt{F_{1}^{2}+F_{2}^{2}+F_{3}^{2}}}{1.732}
$$

Once the CCME WQI value has been determined, water quality is ranked by relating it to one of the following categories as shown in the table 4.0 below.

Excellent: (CCME WQI Value 95-100) - water quality is protected with a virtual absence of threat or impairment; conditions very close to natural or pristine levels.

Good: (CCME WQI Value 80-94) - water quality is protected with only a minor degree of threat or impairment; conditions rarely depart from natural or desirable levels.

Fair: (CCME WQI Value 65-79) - water qualities usually protected but occasionally threatened or impaired; conditions sometimes depart from natural or desirable levels.

Marginal: (CCME WQI Value 45-64) - water quality is frequently threatened or impaired; conditions often depart from natural or desirable levels.

Poor: (CCME WQI Value 0-44) - water quality is almost always threatened or impaired; conditions usually depart from natural or desirable levels.

The assignment of CCME WQI values to these categories is termed "categorization" and represents a critical but somewhat subjective process. The categorization is based on the best available information, expert judgment, and the general public's expectations of water quality.

III. RESULT ANALYSIS AND DISCUSSION HATHINKUND STATION:

The Table: 3.a and Figure 2. Below show the profile of Yearly water quality index (WQI) of Hathikund from 19992005 .

\begin{tabular}{|c|c|}
\hline YEAR & WQI \\
\hline 1999 & 60 \\
\hline
\end{tabular}


Evaluation of Yearly Water quality index and Seasonal Variation of Yamuna River at Hathikund Station

\begin{tabular}{|c|c|}
\hline 2000 & 64.8 \\
\hline 2001 & 66.5 \\
\hline 2002 & 83 \\
\hline 2003 & 66.5 \\
\hline 2004 & 30.5 \\
\hline 20005 & 20.8 \\
\hline
\end{tabular}

Table: 3.a

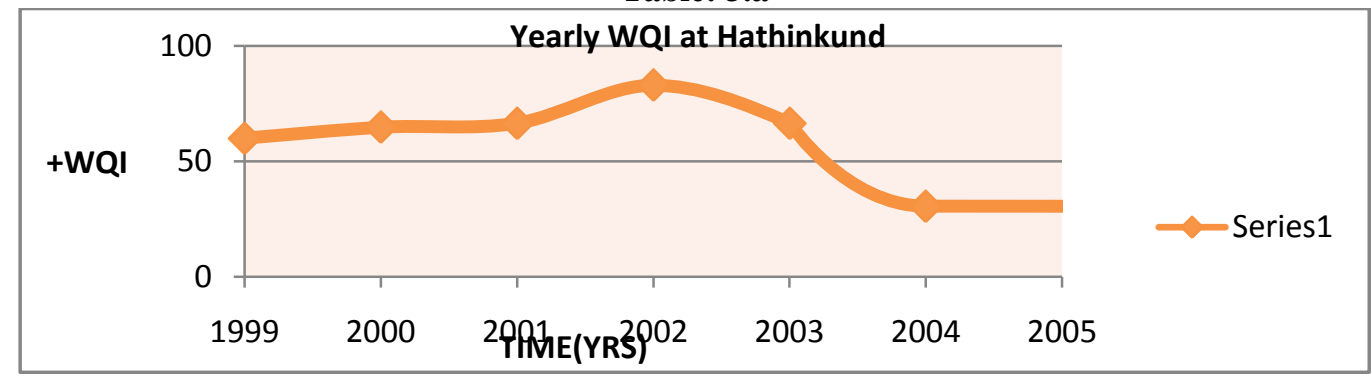

Fig: 2

3.2 Seasonal Variations of Hathikund:

A- Monsoon Period (Jul-Sept): The table 3b and Figure 3 show the profile of WQI from July to September.

\begin{tabular}{|c|c|}
\hline YEAR & WQI \\
\hline 1999 & 41.6 \\
\hline 2000 & 58.6 \\
\hline 2001 & 82.4 \\
\hline 2002 & 100 \\
\hline 2003 & 100 \\
\hline 2004 & 10.4 \\
\hline 20005 & 9.4 \\
\hline
\end{tabular}

Table: $3 \mathbf{b}$

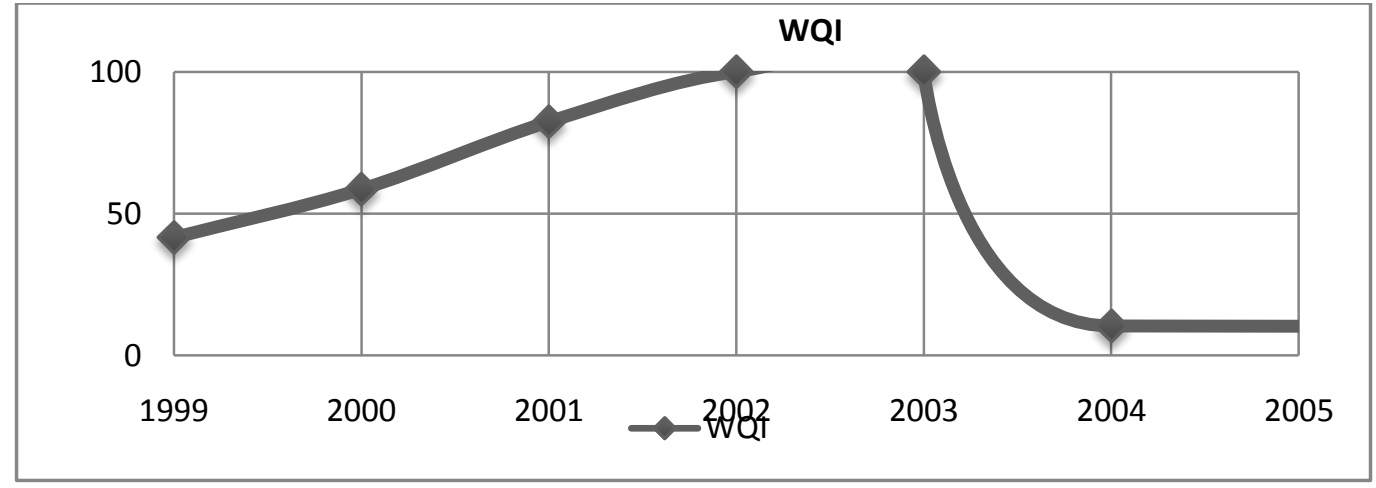

Fig: 3

B - Non-Monsoon Period (JAN-JUN): The table 3c and Figure 4 show the profile of WQI from

\begin{tabular}{|c|c|}
\hline \multicolumn{2}{|c|}{ Jan-Jun } \\
\hline YEAR & WQI \\
\hline 1999 & 100 \\
\hline 2000 & 29 \\
\hline 2001 & 100 \\
\hline 2002 & 100 \\
\hline 2003 & 91.7 \\
\hline 2004 & 30.6 \\
\hline 20005 & 47 \\
\hline
\end{tabular}

Table: 3c 


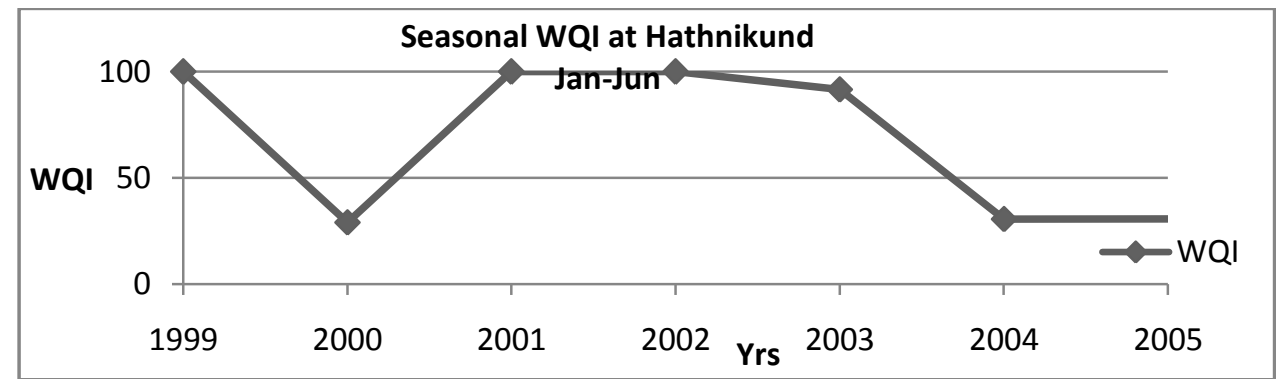

Fig: 4

C - Non-Monsoon Period (OCT-DEC): The Table 3d. And Figure 5 show the profile of WQI from Oct-Dec

\begin{tabular}{|c|c|}
\hline YEAR & WQI \\
\hline 1999 & 81.55 \\
\hline 2000 & 79.8 \\
\hline 2001 & 100 \\
\hline 2002 & 82 \\
\hline 2003 & 100 \\
\hline 2004 & 40 \\
\hline 20005 & 100 \\
\hline
\end{tabular}

Table: 3d

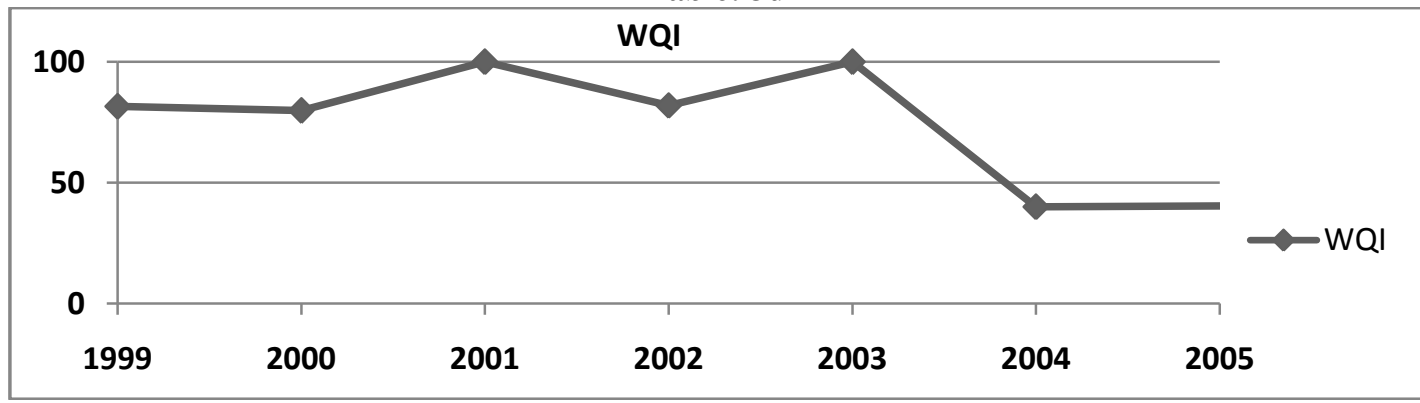

Fig: 5

\section{CONCLUSION}

Close examinations of the Figure 3 shows that:

From the water quality ranking of CCME it was clearly shown that the water quality at Hathikund was fall under the category of Good to Poor with the range of 83-20.8 as shown in the table above. It was also indicate that the year 2002 the water quality is protected with only a minor degree of threat or impairment; conditions rarely depart from natural or desirable levels, in which the WQI was $\mathbf{8 3}$.

In years 2000, 2001 and 2003 the WQI falls under the Fair category with the range of 65-79 which indicate that the WQ sometimes violate the criteria, possibly by a wide margin , for the use as a source of drinking water. Also in year 1999 the WQI fall under the Marginal category with the value of 60, that indicates the WQ is often violate the criteria for the use as a source of drinking water. It was also shows that in 2004 and 2005 the WQI fall under the Poor category with the standard range of 0-44 which indicated that the WQ does not meet any criteria for the use as a source of drinking water.

\section{CONCLUSION OF HATHIKUND SEASONAL VARIATION}

A- $\quad$ During these period of monsoon that is July to September the result indicate that the water quality of Hathikund is deteriorating only in respect of Fecal coli form(FC) and the deterioration occur from 2004-2005 with water quality index value of 10.4-9.4 respectively, and also the severely affected station is 2005.it was observed that the parameters were all the prescribed limit except for the value of FC which are a bit higher than the prescribed limit at 2004 and 2005 as well as a slight declined in the value of water temperature (WT).

B- $\quad$ A close examination of Non-monsoon period indicate that the water quality at 1999, 2001,2002 and 2003 meet all the criteria for the use as source of drinking water except at 2000,2004 and 2005 which fall between Poor and Marginal category, It also indicate that DO concentration ,BOD,AMM,WT, pH and FC are all within the prescribe limit except some slight variation of FC at 2000,2004 and 2005 which is major factors 
that make the water quality not to fall within the prescribe limit. With the year 2000 marked the severely affected stations.

C- $\quad$ The water quality at this season Oct-Dec falls within the category of Excellent and Good in all the year except for the year 2004 in which the WQ is 40 which fall under the Poor category that does not meet any criteria as the source of drinking water, this also indicate that all the parameters are within the prescribe limit sstandard except at 2004 where The FC are above the limit in October and November with slight pH declined at same year and WT at 1990,2000 , and 2002 with the slight value ranges from $26-27^{\circ} \mathrm{C}$.

\section{BIBLIOGRAPHY}

[1] Wreta Qyrileu Ixetn fo Babolrood River in Mazandaran, Iran. Behmanesh, Ali and Feizabadi2, Yaser. 2013, International Journal of Agriculture and Crop Sciences, pp. /2285-2292. ISSN 2227-670X.

[2] An Innovative Index for Evaluating Water Quality in Stream. SAID, AHMED, STEVENS, DAVID K. and SEHLKE, GERALD. 2004, pp. 406-414.

[3] An innovative index for evaluating water quality in streams . A, Said, DK, Stevens and G, Sehlke. 2004, SPRINGFER :https://www.ncbi.nlm.nih.gov/pubmed/15520897, pp. 406-14.

[4] Application of CCME Water Quality Index to Monitor Water Quality: A Case Study of the Mackenzie River Basin, Canada. LUMB, ASHOK, HALLIWELL, DOUG and SHARMA, TRIBENI. 2006, @ Springer 2006, pp. 411-429.

[5] APHA.Standard methods for the examination of water and wastewater. Washington D.C : 22nd 2012 / prepared and published jointly by American Public Health Association, American Water Works Association, Water Environment Federation, 2012.

[6] Water quality and uses of the Bangpakong River (eastern Thailand). AA, Bordalo, W, Nilsumranchit and K, Chalermwat. 15, US : US National library of Medine, 2001, Vol. 35.

[7] Canadian Water Quality Guidelines for the Protection. CANADA : CCME WATER User's Manual, 2001.

[8] CENTRAL POLlution CONTROL BOARD Ministry of Environment \& Forests Parivesh Bhawan, East Arjun Nagar, Delhi-110 032.STATUS OF WATER QUALITY IN INDIA. INDIA : CENTRAL POLLUTION CONTROL BOARD, 2009.

[9] Alobaidy, Abdul Hameed M. Jawad, Maulood, Bahram K. and Kadhem, Abass J.Evaluating Raw and Treated Water Quality of Tigris River within Baghdad by Index Analysis . s.1. : J. Water Resource and Protection, 2010.

[10] DESIGN OF AN INDEX OF WATER QUALITY. Dinius, S. H. 1752-1688, s.1. : Journal of American Water Resources, 1987. 86088.

[11] Water Quality Assessment in Terms of Water Quality. Tyagi, Shweta, et al., et al. 3, America : American Journal of Water Resources,Science and Education Publishing, 2013, Vol. 1.

[12] Revival of Mathura's ailing Yamuna river. Bhargava, Devendra S. INDIA : Springer Science + Business Media, LLC 2006, 2006. 10669-006-7481-1.

[13] S.I. Abba 'Assessment of Water Quality Changes at Two Location of Yamuna River Using the National Sanitation Foundation of Water Quality (NSFWQI)" Journal of Civil Engineering and Environmental Technology Print ISSN: 2349-8404; Online ISSN: 2349-879X; Volume 2, Number 8; April-June, 2015 pp. $730-733$

[14] "Appraisal of Yearly And Seasonal Water Quality Variation At Chambal River Using Canadian Counsel of Minister Of Environment Model" International Journal of Advance Research In Science And Engineering. Vol. 4. Issue 01.S.I. Abba. 